\title{
Functionalization of cyclic natural rubber grafted maleic anhydride (cnr-g-ma) with variation of ma concentration, inisiator and reaction time
}

\author{
Boy Chandra Sitanggang ${ }^{1, *}$ and Eddyanto ${ }^{2}$ \\ 'Program Studi Analisis Kimia, Akademi Komunitas Industri Manufaktur Bantaeng, Bantaeng, Indonesia \\ ${ }^{2}$ Department of Chemistry, Universitas Negeri Medan, Medan 20221, Indonesia
}

${ }^{*}$ Corresponding author: (BCS), boycsitanggang@kemenperin.go.id

DOI: 10.24l14/jpkim.vlli3.15736

Received: 2 October 2019; Accepted: 27 November 2019

Abstract:

Cyclic natural rubber have low compatibilities when mixed with other polymer. The compatibility of a cyclic natural rubber (CNR) could be increased through grafted functional monomer to the polymer backbone. This research aims to know about influence of maleic anhydrate concentration (3-15 phr) as monomer, concentration of benzoyl peroxide (0.05-0.2 molar ratio) as initiator and times (15-90 minute) towards grafting degree of maleic anhydride. The research conducted with reflux in oil bath, at constant temperature $110^{\circ} \mathrm{C}$. The grafting degree determined with titration method and FTIR analysis used to show the existence of grafted maleic anhydrate onto cyclic natural rubber. Result of FTIR analysis showed that grafted anhydrate to cyclic natural rubber assigned with the presence of carbonyl absorptions ( $\mathrm{C}=\mathrm{O}$ stretching). Result titration showed that concentration of maleic anhydrate and benzoyl peroxide enhanced as well as grafting degree. While for variation of time, optimum grafting degree achieved at 60 minute.

Keywords: Grafting; inisiator; natural rubber; polymer

\section{Introduction}

Cyclic natural rubber is derivative material from natural rubber, it becomes prime product from downstream of rubber industry. Because of the characteristics such as waterproof, resistance to weak and strong acids, alkalines, salts and other corrosive chemicals. Thus, cyclic natural rubber widely used in commercial applications as adhesive, printing inks, industrial and ship paints. Cyclic natural rubber is produced from natural rubber by treatment with strong acids or Friedel-Crafts catalyst. As reaction proceeds there is a progressive loss in elasticity until eventually a hard, brittle material is formed. However, the process gives partial cyclization. Means, there is double bond remained from polyisoprene as natural rubber polymer backbone. Study about cyclic natural rubber structure that produced can be in the form of mono-, bi-, also polycyclic. This matter depend on reaction condition and the nature of the solvent (Golub et al. 1963; Saunders, 1988; Mojgan, 2000; Riyajan et al. 2006; Sitanggang et al. 2016).

Cyclic natural rubber is non polar polymer with low energy surface, so that causes low interface interaction and adhesive character especially when mixed with polar polymer. Equally, cyclic natural rubber is not compatible towards polar polymer like fiber and animal skin. To overcome this troubleshoot, chemical modification of cyclic natural rubber structure becomes important. The introduction of new monomer in polymer chain will causes denaturing from the original structure so that polymer that transplanted can interacted with both of polar polymer and non polar. 
Peroxide initiators have no such resonance stabilization exists and higher grafting yield should be obtained. Batthacarya \& Misra (2004). Modification of polymers through grafting with functional monomer is a relative simple method and the most readily available method among those developed in recent years. Widely, grafting technique have done by many researcher to increase compatibility in reactive blending. Various substance have been used as monomer in various polymer backbone by using grafting method (Eddyanto, 2007; Nakason et al. 2002; Nakason et al. 2004; Nakason et al. 2006; Krump et al. 2005; Yohan et al. 2006; Ferrero, 2005; Valsa et al. 2003.

\section{Materials and Methods}

\section{Material}

The cyclo natural rubber (Resiprene-32) manufactured by PTPN IIl. Another chemicals which used are: aquades, benzoyl peroxide (BPO), maleic anhydrate (MA), methanol, phenolphthalein, toluene. All chemicals are pro analysis grade without further purification and produce by Merck except methanol is use both technical grade and pro analysis. FTIR was used to determine functional groups.

\section{Grafting process}

The grafted CNR was synthesized in a solution state. In the typical solution-grafting process, $5 \mathrm{~g}$ of dried CNR are dissolved in $150 \mathrm{ml}$ toluene at $60^{\circ} \mathrm{C}$. After complete dissolve of the CNR, MA (3, $6,9,12,15 \mathrm{phr})$ and the free radical initiator BPO $(0.05,0.1,0.2$ molar ratio) are added. The reaction was allowed to proceed at the desired reaction time $(15,30,60,90$ minutes) under continuous stirring to complete the graft copolymerization. After that, cooling down until room temperature achieve. The graft copolymer solution was precipitated by adding methanol at room temperature. After thoroughly washing with methanol, the graft copolymer was transferred to an oven at $40^{\circ} \mathrm{C}$ for $\mathrm{ca} 24 \mathrm{~h}$ to remove any trace of residual solvent and maleic anhydride.

\section{Determination of grafting degree}

The quantity of MA grafted onto the NR molecules was determined by titration of acid groups derived from the anhydride functions. After dissolve of $1.0 \mathrm{~g}$ of CNR-g-MA in $100 \mathrm{ml}$ of toluene at boiling temperature, $0.2 \mathrm{ml}$ of water was added to hydrolyze anhydride functions into carboxylic acid functions. Then the solution was refluxed for $1.0 \mathrm{~h}$ to complete the hydrolysis. The carboxylic acid concentration was determined by titration with $0.05 \mathrm{~N}$ potassium hydroxide in methanol. The indicator used is a solution of $1 \%$ phenolphthalein in methanol. The carboxylic acid concentration was converted to the grafted MA as follows:

$M A$ grafting deg. $(\% w t)=\frac{\left(\mathrm{V}_{1-} \mathrm{V}_{0}\right) \cdot \mathrm{N}}{2 \mathrm{~W}_{\mathrm{s}} \times 1000} \times M \mathrm{~W}_{M A} \times 100$

Where $N$ is the concentration (meq/L) of potassium hydroxide dissolved in methanol. $V_{0}$ and $V_{l}$ are the volumes of the $\mathrm{KOH}$ used in the blank test and in the test with samples, respectively. $W s$ is the weight ( $\mathrm{g}$ ) of the CNR-g-MA sample. 2 is conversion factor of two carboxylic acid formed from 1 molecule MA.

\section{Determination of grafting efficiency}

Grafting Efficiency (\%) is the percentage ratio of the amount of a functional monomer that becomes grafted onto a polymer to the amount of the same functional monomer initially added to the polymer.

$$
\text { Grafting efficiency }(\%)=\frac{\text { mass of grafted monomer }(\mathrm{g})}{\text { mass of } M A \text { initially } \operatorname{added}(\mathrm{g})} \times 100
$$


Functionalization of cyclic natural rubber grafted maleic anhydride (cnr-g-ma) with variation of ma concentration, inisiator and reaction time

\section{Results}

\section{Effect of MA concentration on the grafting degree and grafting efficiency}

The graph of grafting degree versus MA concentration is given in Fig 1 and Fig 2. The graph shows that grafting degree increase with increasing MA concentration.

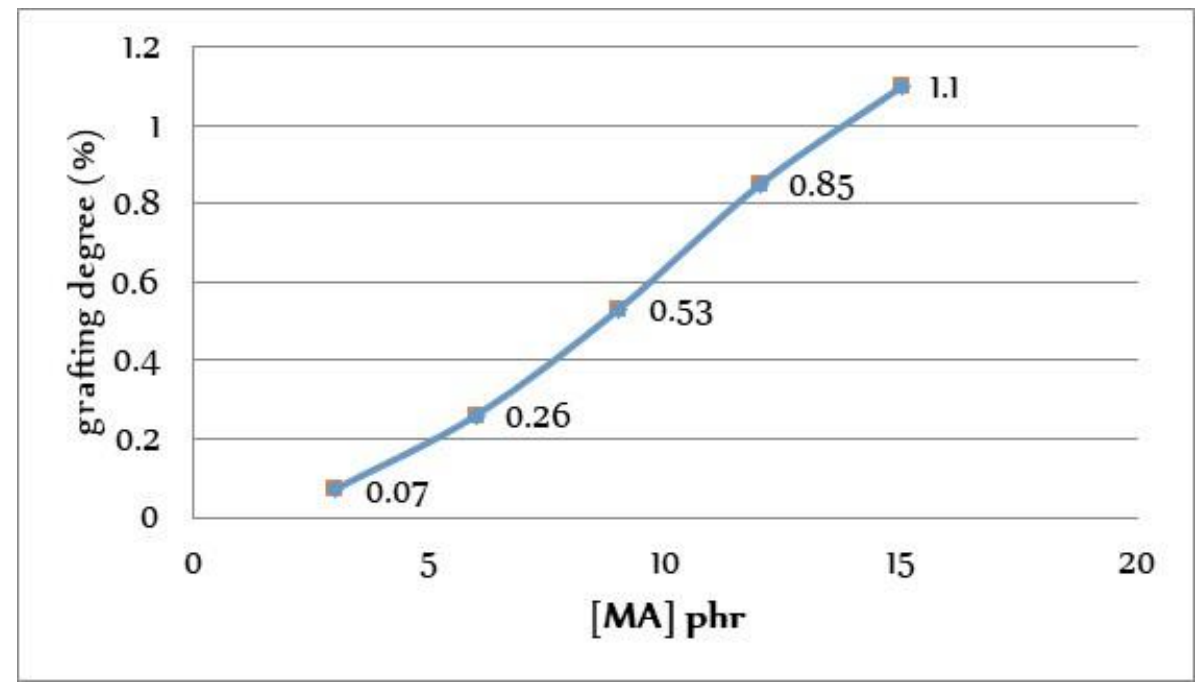

Fig 1. MA concentration versus grafting degree (\%)

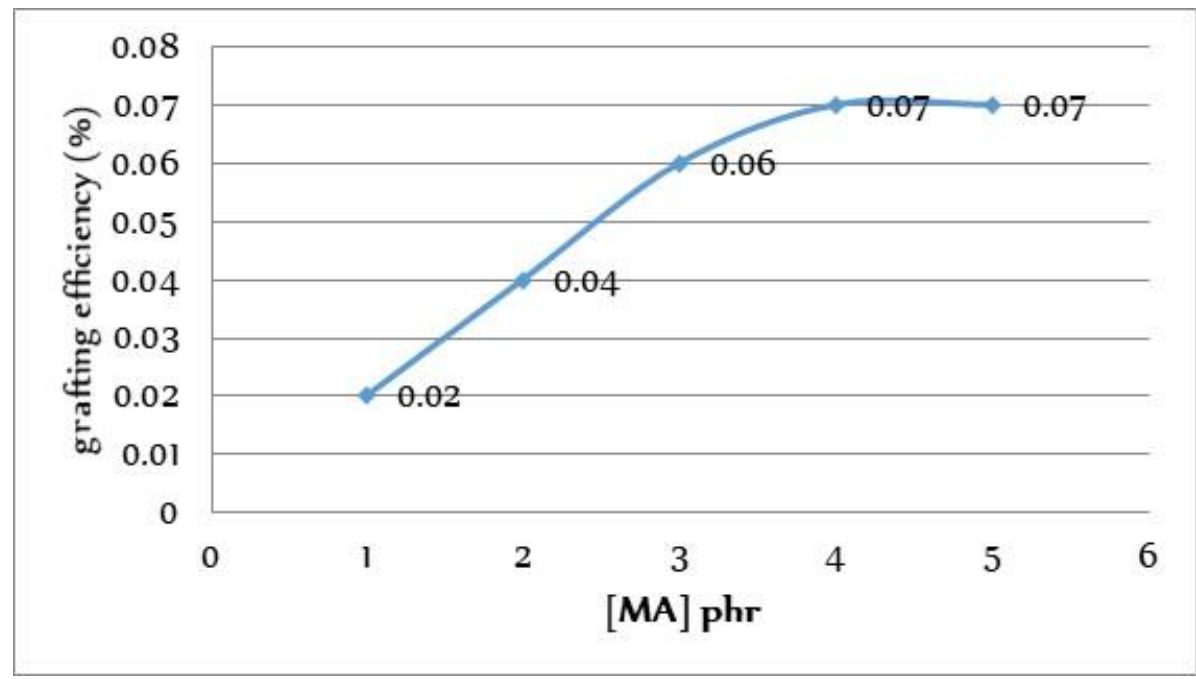

Fig 1. MA concentration versus grafting efficiency (\%)

\section{Effect of BPO concentration on the grafting degree}

Figure 3 and Fig 4 show that higher BPO concentration then higher grafting degree achieved. 
Functionalization of cyclic natural rubber grafted maleic anhydride (cnr-g-ma) with variation of ma concentration, inisiator and reaction time

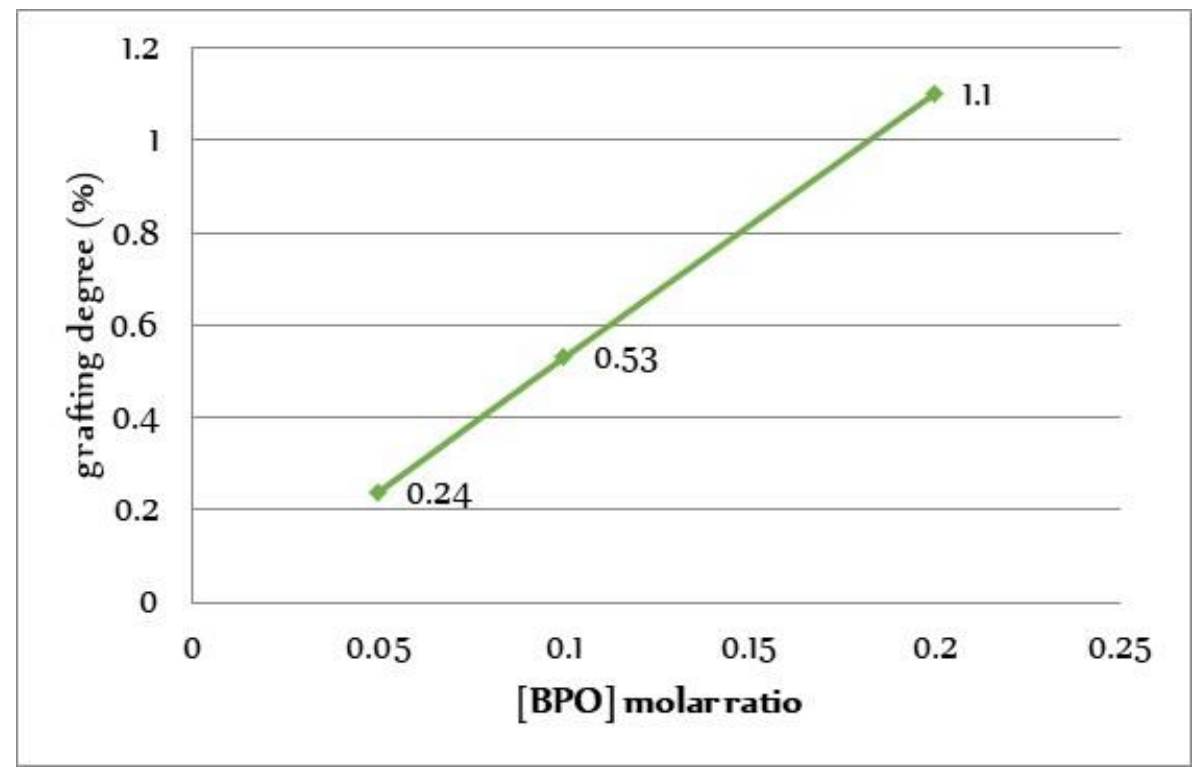

Fig 3. BPO (inisiator) concentration versus grafting degree (\%)

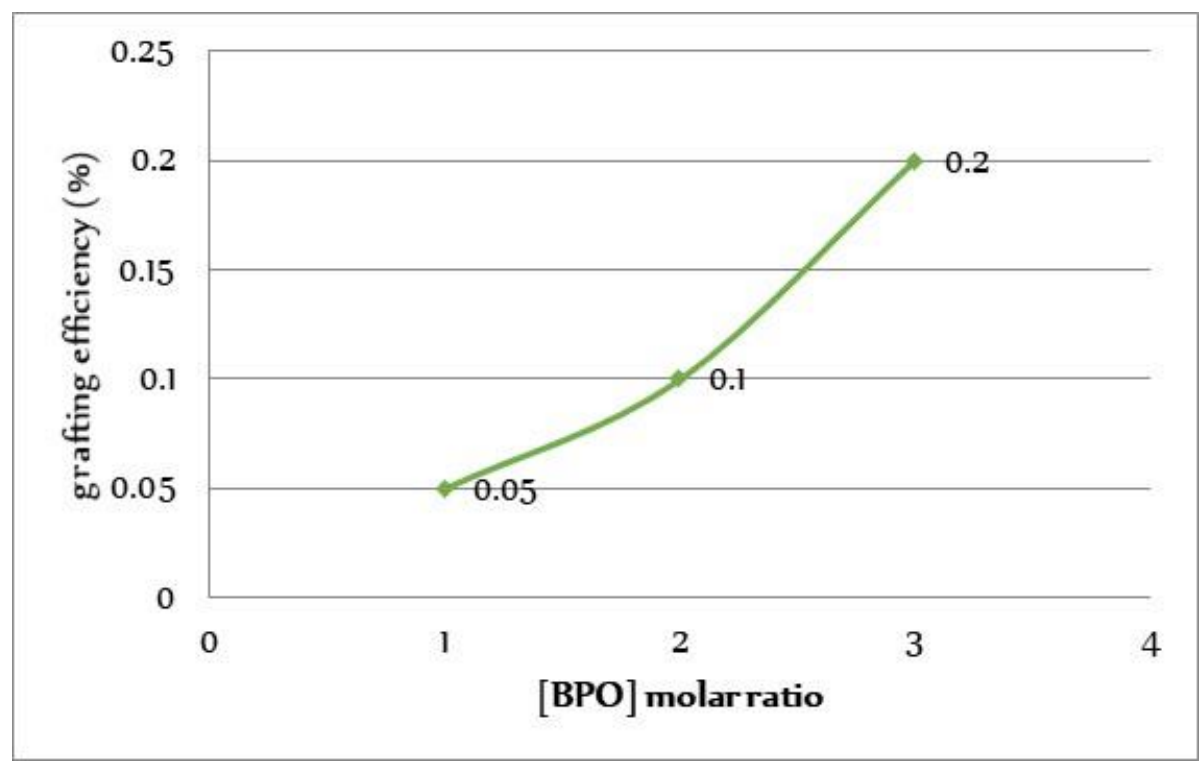

Fig 4. BPO concentration (molar ratio) versus grafting efficiency (\%)

\section{Effect of times on the grafting degree}

In order to study the time-dependent behavior of the MA grafting onto $\mathrm{CNR}$, the amount of reactants were fixed $([\mathrm{MA}]=9 \mathrm{phr}$, and $[\mathrm{BPO}]$ at 0.05-0.2 molar ratio to $\mathrm{MA})$ and processed at constant temperature of $110^{\circ} \mathrm{C}$.

The optimum point reached at 60 minute (Fig 5 and Fig 6). The percentage of conversion of MA monomers increased rapidly in 20 to 60 minutes, after which the extent of increase then dropped at 90 minute.

The graph of grafting efficiency is given below, it's show flat line at range 15-60 minutes then sharply drop at 90 minute. 
Functionalization of cyclic natural rubber grafted maleic anhydride (cnr-g-ma) with variation of ma concentration, inisiator and reaction time

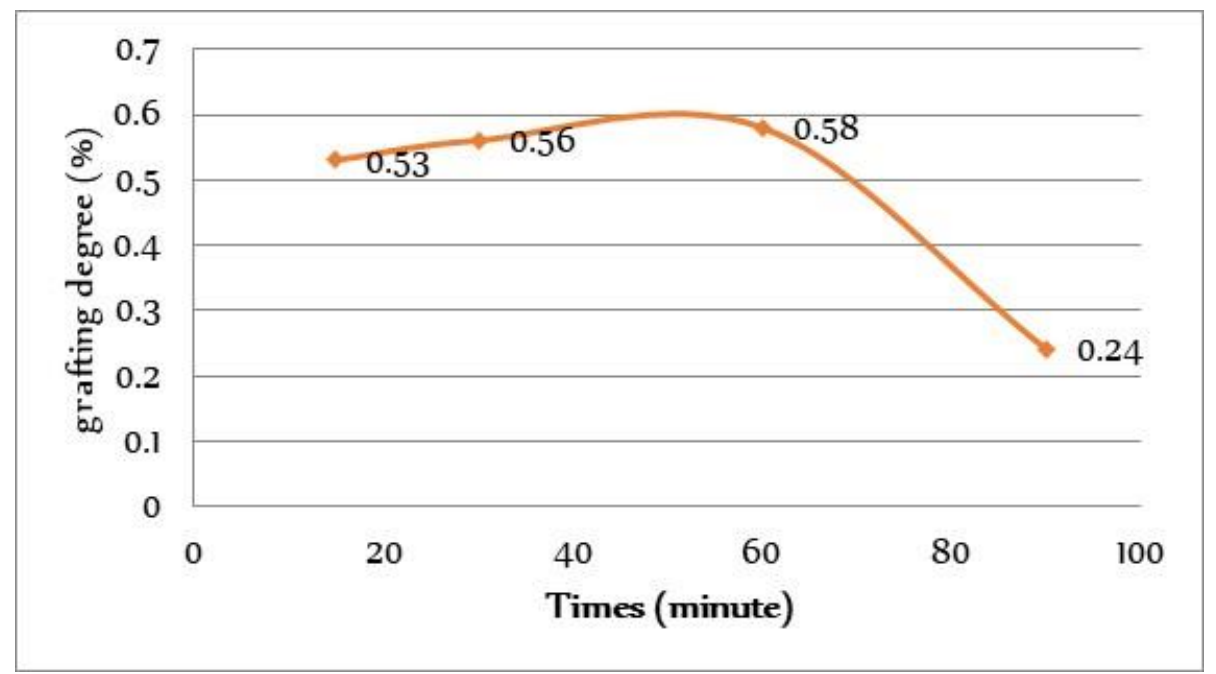

Fig 2. Time versus grafting degree (\%)

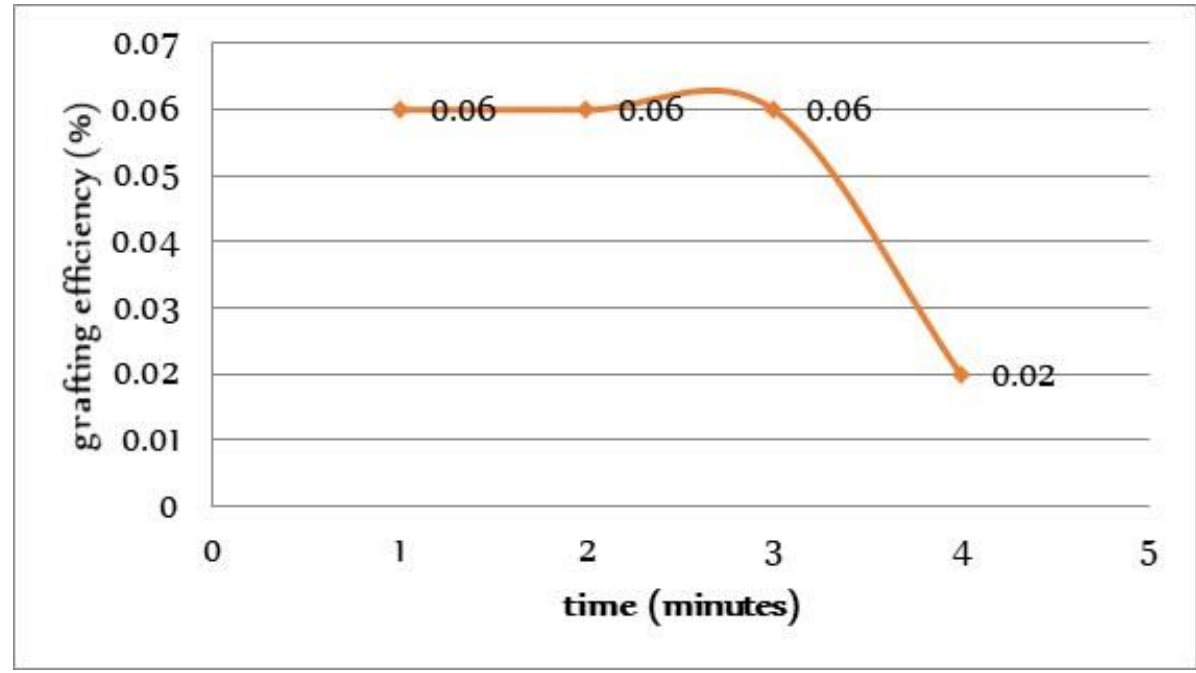

Fig 6. Time (minutes) versus grafting efficiency (\%)

\section{FT7R characterization}

The ftir characterisation CNR shows following wavenumbers $\left(\mathrm{cm}^{-1}\right): 2929(\mathrm{CH}$ strech), $1596(\mathrm{C}=\mathrm{C})$, 1457 and 1374 ( $\mathrm{CH}$ bend). Meanwhile, CNR-g-MA give the following results $3438(\mathrm{OH}), 2923(\mathrm{CH}$ strech), 1606 (C-O), 1459 dan 1375 ( $\mathrm{CH}$ bend).

\section{Discussion}

The grafting degree is dependent upon the initiator concentration as well as the monomer and the polymer backbone (CNR). The higher amount of MA monomers added to reaction create more monomer attacked by CNR radical therefore higher CNR grafted MA were produced. The presence of the initiator also need to be considered since the initiation of CNR radical depend on the amount of initiator, in this case benzoyl peroxide. The measurement of initiator widely were using percent of weight directly compared to polymer so the amount of initiator stay constant (Batthacarya \& Misra, 2004). In this research molar ratio of initiator to MA was used. Therefore, 
increasing MA weight as well as increase BPO concentration (Eddyanto, 2007). Fig 1 illustrate the phenomenon. However, BPO decomposition leads to a larger formation of primary and secondary radical as benzoyl radical and phenyl radical respectively. Phenyl radical more stabile then benzoyl radical. So, those radicals will compete each other. Hence, when phenyl radical formed, the grafted MA to CNR could stop and yield another form. That is explain the maximum grafting efficiency achieved at $0.7 \%$.

Fig 3 show that higher BPO concentration then higher grafting degree achieved. It was predicted due to amount of initiate radical would increase CNR radical attacking MA monomer furthermore. Once a certain initiator concentration was reached, higher levels of initiator do not increase the conversion of grafted monomer. Fig 5 exhibit the optimum point at 60 minute. The percentage of conversion of MA monomers increased rapidly in 20 to 60 minutes, after which the extent of increase then dropped at 90 minute. This matter may be caused by competition of MA homo-polymerisation where MA monomers form poly (MA), chain scission of CNR, disproportion and cross linking. The radical half-life time also considered as reason of the decreasing grafting level after 60 minute. Where $\mathrm{BPO}$ half-life time at $100^{\circ} \mathrm{C}$ is 30 minute.

The probability of mechanism (Fig 7-12) reaction begin with decomposition of benzoyl peroxide form two peroxide radical. Next, by the $\mathrm{H}$ abstraction the initiation started. Of course this attack can not be controlled, the probability of $\mathrm{H}$ abstraction that given here only at secondary $\mathrm{H}$ because it fairly easier to abstract rather than primary $\mathrm{H}$. The chosen CNR structure is monocyclic due to structure and complexity (Eddyanto, 2007); Nakason et al. 2004). Afterwards, macro radical (CNR radical) attack MA monomer form CNR-g-MA radical. Resulted CNR-g-MA radical attack another polymer backbone, it could be form CNR-g-MA via chain transfer or yield cross linking. Radical fusion terminate the reaction.

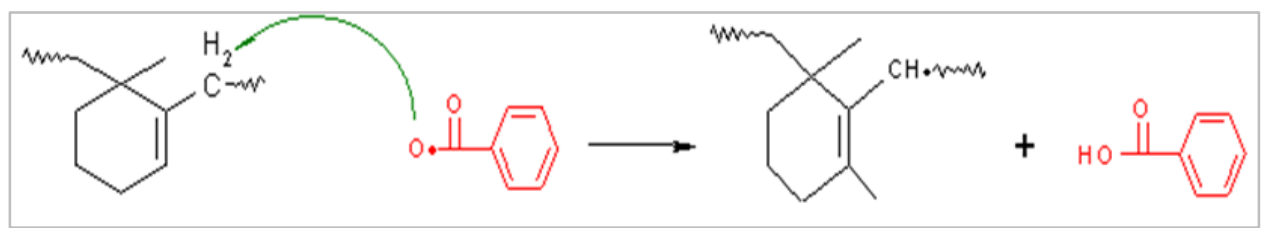

Fig 3. Initiation

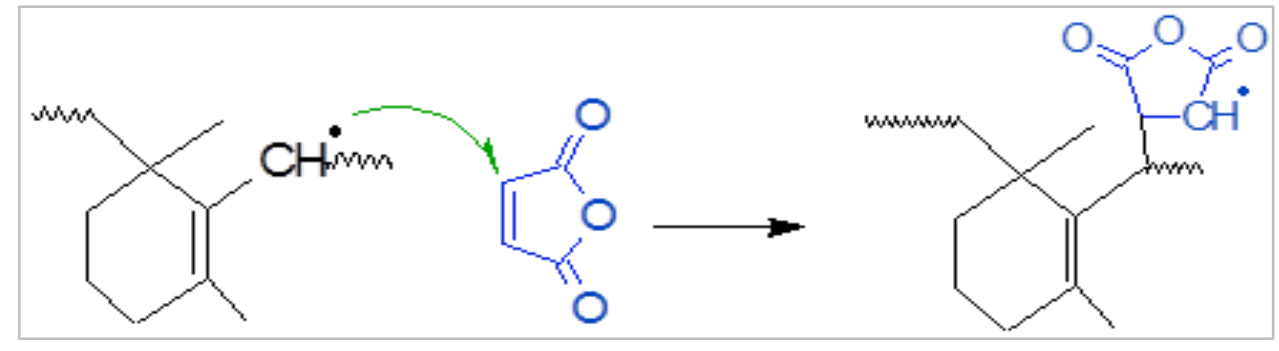

Fig 4. Propagation

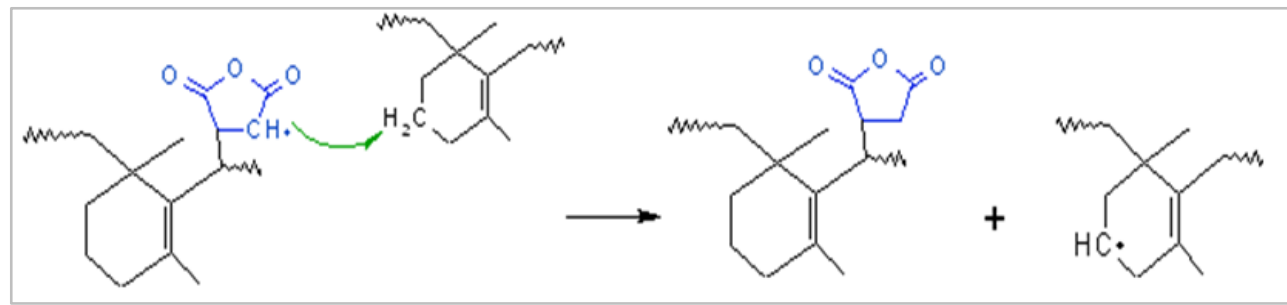

Fig 5. Chain transfer 


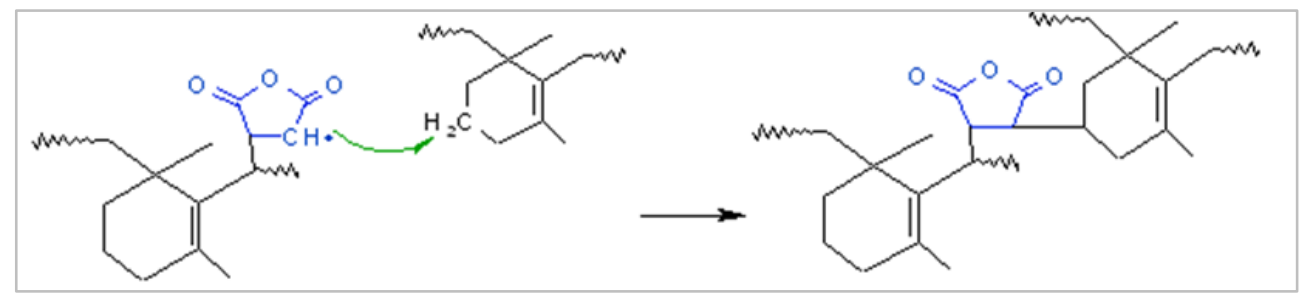

Fig 6. Cross link

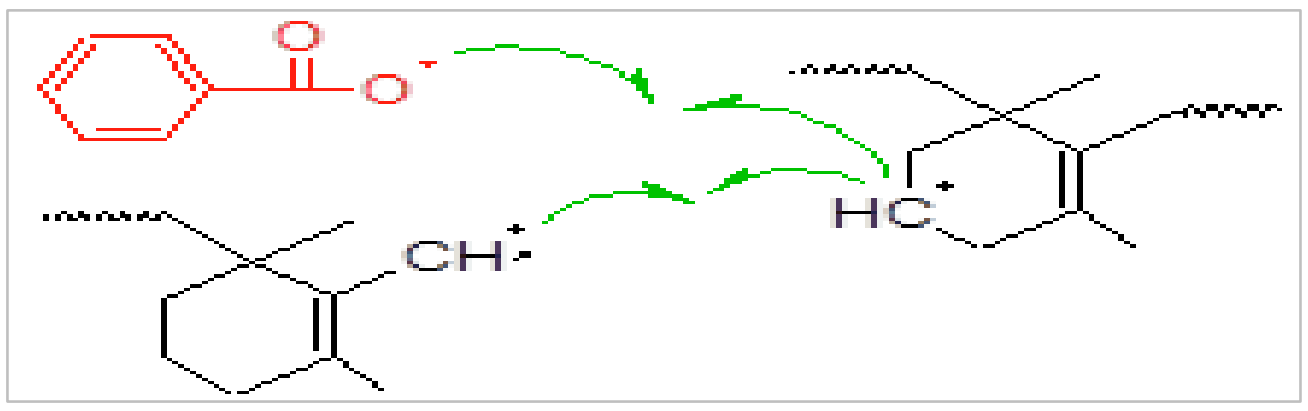

Fig 7. Termination

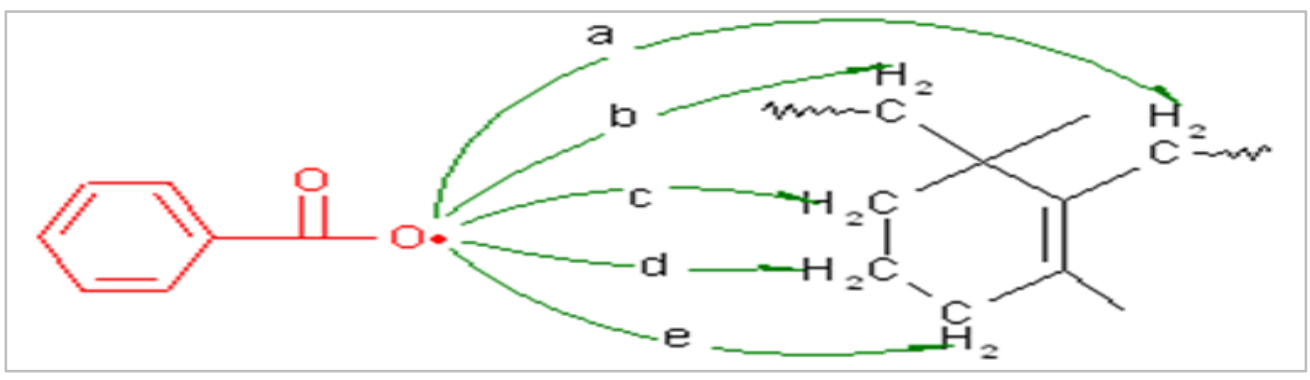

Fig 8. Probability of radical attacking

\section{Conclusion}

The variation amount of MA linier to the grafted result, however, the efficiency limited to a certain amount. BPO used in given range show an increasing tendency of the CNR-g-MA, it's consistent with other researcher that initiate radical would increase. Once the optimum time reached, the grafting results slowing down.

\section{References}

Bhattacharya, A., \& Misra, B. N. (2004). Grafting: a versatile means to modify polymers: techniques, factors and applications. Progress in Polymer Science, 29(8), 767-814, doi: 10.1016/j.progpolymsci.2004.05.002

Eddyanto. (2007). Functionalitation of polymers: reactive processing, structure and peformance characteristics, Thesis, Aston University.

Ferrero, F. (2005). Solvent effect in grafting of liquid polybutadienes with maleic anhydride. Progress in organic coatings, 53(1), 50-55, doi: 10.1016/j.porgcoat.2004.12.009

Ginting, S. N., Simanullang, E. K., Simanullang, L. P., Nainggolan, B., \& Silaban, S. (2018). The optimization of acid hydrolysis on bioethanol production from durian peel waste (Durio zibethinus murr). Jurnal Pendidikan Kimia, 10, 382-386, doi: 10.24114/jpkim.v10i2.10917

Golub, M. A., \& Heller, J. (1963). The reaction of polyisoprene with titanium tetrachloride. Canadian Journal of Chemistry, 41(4), 937-953, doi: 10.1139/v63-133 
Krump, H., Alexy, P., \& Luyt, A. S. (2005). Preparation of a maleated Fischer-Tropsch paraffin wax and FTIR analysis of grafted maleic anhydride. Polymer Testing, 24(2), 129-135, doi: 10.1016/j.polymertesting.2004.09.011

Mojgan, M. (2000). The cyclization of natural rubber. Iran J. Chem.\& Chem. Eng, 19(2), 91-96.

Nakason, C., Saiwaree, S., Tatun, S., \& Kaesaman, A. (2006). Rheological, thermal and morphological properties of maleated natural rubber and its reactive blending with poly (methyl methacrylate). Polymer testing, 25(5), 656-667, doi: 10.1016/j.polymertesting.2006.03.011

Nakason, C., Kaesaman, A., \& Supasanthitikul, P. (2004). The grafting of maleic anhydride onto natural rubber. Polymer Testing, 23(1), 35-41, doi: 10.1016/s0142-9418(03)00059-x

Nakason, C., Kaesaman, A., Samoh, Z., Homsin, S., \& Kiatkamjornwong, S. (2002). Rheological properties of maleated natural rubber and natural rubber blends. Polymer Testing, 21(4), 449-455, doi: $10.1016 / \mathrm{s} 0142-9418(01) 00109-x$

Riyajan, S., \& Sakdapipanich, J. T. (2006). Cationic cyclization of deproteinized natural rubber latex using sulfuric acid. KGK-Kautschuk, Gummi, Kunststoffe, 59(3), 104-109.

Riyajan, S., Tuampoemsab, S., \& Sakdapipanich, J. T. (2008). Dynamic mechanical and physical properties of cyclized natural rubber blends. KGK-Kaust Gummi Kunststoffe, 61, 665-670.

Saunders, K. J. (1988). Organic polymer chemistry. Second Edition, Blackie Academic \& Professional, Glasgow.

Sitanggang, B. C., Wirjosentono, B., \& Ginting, M. (2016). Preparationof Fe-chitosan schiff base complex. Jurnal Pendidikan Kimia, 8(3), 203-206.

Yohan, N. R., Hendrajaya, R., \& Siradj, E. S. (2006). Sintesis kopolimer tercangkok asam akrilat pada film LLDPE. Jurnal Kimia Indonesia, 1(1), 32-38.

George, V., Britto, l. J., \& Sebastian, M. S. (2003). Studies on radiation grafting of methyl methacrylate onto natural rubber for improving modulus of latex film. Radiation physics and chemistry, 66(5), 367372, doi: 10.1016/s0969-806x(02)00390-0 